\title{
Insecticidal Potency of Aqueous Extracts of Seeds and Leaves of Harmal Peganum Harmala (Zygophyllaceae) on Juveniles of Calliptamus Barbarus (Orthoptera: Calliptaminae): Contact and Ingestion Effects
}

\section{Rouibah $\mathbf{M}^{*}$ \\ Department of Environment science, University of Jijel, Algeria}

*Corresponding author: Moad Rouibah, Department of Environment science, University of Jijel, Algeria, Email: rouibahm@yahoo.com

\section{Investigation Paper}

Volume 2 Issue 6

Received Date: December 13, 2019

Published Date: December 31, 2019

DOI: $10.23880 /$ izab- 16000196

\section{Abstract}

This work is a study on the insecticidal effect of aqueous extracts of seeds and leaves of Harmal Peganum harmala on both of two larvae L2 and L3 of barbarian locust Calliptamus barbarus (Orthoptera: Acrididae). GCP analysis revealed the presence of 12 -benzenedicarboxylic acid, diisooctyl ester as the most frequently constituents found in the plant.

Treatments on $C$. barbarus have been performed by two ways: contact and ingestion. Contact allowed us to obtain a cumulative mortality rate (after 3 days of treatments) which was $90 \%$ for a highest dose (2.4 g/l ) with an LD 50 of $0.67 \mathrm{~g}$ $/ \mathrm{l}$ for AqE seeds and $50 \%$ of mortality with $3.01 \mathrm{~g} / \mathrm{l}$ for leaves.

By ingestion and after 6 days of treatments, the cumulative mortality rate for the dose of $2.4 \mathrm{~g} / \mathrm{l}$ and the LD 50 of AqE seeds were respectively $90 \%$ and $0.45 \mathrm{~g} / \mathrm{l}$. For leaves, these were $70 \%$ and $0.85 \mathrm{~g} / \mathrm{l}$.

The comparative effect of contact and ingestion tests between the two "bioactive extract" by their respective LD 50 show that seeds AqE are more effective than leaves.

This difference in mortality rate is due mainly to the variation in the contents in the various organs of the plant more important in seeds than leaves. Concerning the modes of action we noted that after 3 days of contact treatment, a result $(90 \%)$ similar to that recorded 6 days after ingestion treatment is obtained for seeds. This difference in mortality time is interpreted by the faster mode of penetration by contact than by ingestion.

Keywords: Calliptamus Barbarus; Peganum Harmala; Aqueous Extracts; Seeds; Mortality; Lethal Dose 


\section{International Journal of Zoology and Animal Biology}

\section{Introduction}

Food safety is mainly based on the protection of crops against bio-aggressors, including Orthoptera. Among the Calliptaminae, Calliptamus barbarus is the most polymorphous species. It has a chromatic and geographical polymorphism [1-4]. In addition, it is a dangerous species causing a lot of damage in Algeria.

In agriculture, the protection of crops against pests, weeds and diseases is generally achieved through chemical control. This is based on the application of various phytosanitary products of synthesis [5] Unfortunately, these chemicals cause health and environmental problems. The cause is the contamination of natural environments by non-degradable polluting molecules.

For these reasons, it is therefore urgent to propose alternative solutions such as the use of natural pesticides. These pesticides are based on the extraction of "bioactive extract" from plants. Currently, this use is very widespread in the world hence the interest of this study. In order to control the larvae of $C$. barbarus, the choice was made on a plant species known for its therapeutic virtues. It is the Harmal: Peganum harmala (Zygophyllaceae).

it should be noted that studies on the action of harmal on C. barbarus are absent, however on Schistocerca gregaria several research works has already been successfully carried out on this plant either on L5 or on adults acting by contact or ingestion, we can note among others those of Idrissi Hassani, et al. [6], Benzara, et al. [7]. Kemassi, et al. [8,9], as well as those of Abbassi, et al. $[10,11]$. For their part Idrissi Hassani, et al. [12] conducted a study on the Effects of oil and extracts of $P$. harmala leaves applied under the pronotum of S. gregaria. On their side Idrissi hassani, et al. [13] carried out a histological study about the action of Harmal on the digestive tract of Desert Locust. Finally, concerning the Migratory Locust Locusta migratoria it is necessary to point out the study of Benzara, et al. [14] having tested successfully the effect by contact of " Harmal " seeds on the migratory locust L5.

The aim of this study is to test the insecticidal potency of aqueous extracts of seeds and leaves of $P$. harmala against the juveniles of the locust $C$. barbarus by two methods: the direct contact and their effect by ingestion.

\section{Material and Methods}

The "bioactive extracts" tested are the aqueous extracts (AqE) of seeds and leaves. Two processes were required for the extraction of the active ingredients. The method of maceration was chosen with a view to obtaining the extracts (mainly the alkaloids).

Once the substances are obtained, their yield is calculated and their chemical composition analyzed before testing their insecticidal effect.

\section{Preparation of Extracts Based on Seeds and Leaves: Maceration Protocol}

The seeds were firstly cleaned of impurities, washed with tap water and dried in the dark for a few days. They are then ground (using an electric mixer) into a moderately fine powder, from which the various extracts have been prepared. The aqueous extract (AqE) is obtained according to the method described by Mbiantcha, et al. [15], with some modifications. Maceration is done with $100 \mathrm{~g}$ of the grain powder in 1000 $\mathrm{ml}$ of warm distilled water for 3 days. Filtration on hydrophilic cotton and then on Wattman paper was carried out. For the evaporation of distilled water, the filtrate is placed in an oven at $45^{\circ} \mathrm{C}$. until an extract is obtained which is subsequently stored at $4^{\circ} \mathrm{C}$ in a freezer until it reaches its use. The raw extraction was carried out with $80 \%$ methanol ( $10 \mathrm{~g}$ of grain powder / 100ml) for 24 hours at ambient temperature and protected from light. A second maceration is carried out after filtration on hydrophilic cotton and then through Watt man paper. The filtrates are recombined and then evaporated (by a rotary evaporator) almost dry. The final residues are dried in an oven as described previously [15].

\section{Efficacy Tests}

Prior to testing the effectiveness of "bioactive extracts", C. barbarus larvae were placed in rearing cages. They should be fed with wheat seedlings supplemented with bran [7]. To perform the tests, the larvae were isolated in batches of 10 individuals in insect boxes. The experimental conditions in the laboratory are almost the same as those in the field (temperature, photoperiod and relative humidity). The treatments were carried out by direct spraying on insects in captivity or mixed with food. Four doses of active ingredient were used per liter of distilled water: $0.3,0.6,1.2$ and $2.4 \mathrm{~g} / \mathrm{l}$. Two methods of treatment are used: contact and ingestion. Contact treatment involves spraying the product directly onto the 
larvae. The second method is based on the treatment of insect foods. Note to confirm the biological tests, two controls are used. One negative (distilled water) and the other positive, an insecticide (ACEPLAN 20). To do this, 16 boxes of insects in total are used, one box per dose.

For contact treatment, the results (counts of dead individuals) were read 1, 2 and 3 days after spraying the product. For treatment by ingestion, and in order to allow the product to act against insects, the reading was done 2 ,
4 and 6 days after the application of the product.

\section{Results}

\section{Performance in "Bioactive Extracts"}

Five types of extracts (E) are prepared: two for seeds (aqueous Aq and methanolic Mt) and three for leaves (aqueous, methanolic and acetonic Ac). The yield of these extracts is calculated relative to $100 \mathrm{~g}$ of dry matter for each type. The results are shown in Figure 1.

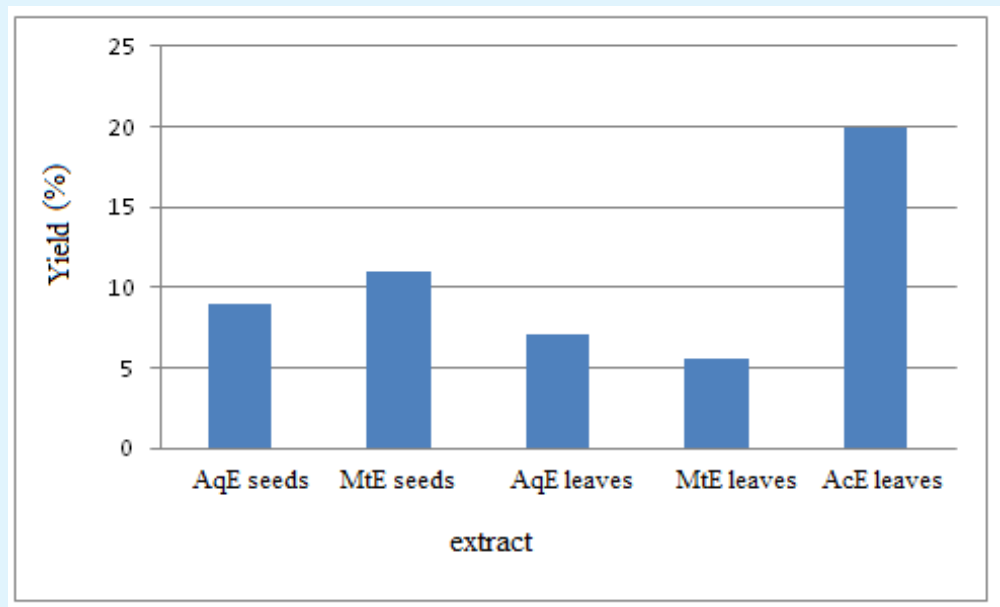

Abbreviations: AqE seeds: aqueous extracts of seeds, BrE grains: methanolic extracts of seeds, AqE leaves: aqueous extracts of leaves, MtE leaves: methanolic extracts of leaves, AcE leaves: Acetonic extracts of leaves.

Figure 1: Yield of the different extracts of P. Harmala.

These results show that the yield of different macerates differs according to the reagent used and the part of the plant concerned. The highest yield $(20 \%)$ is obtained by acetone from the leaves. It is followed by methanolic and aqueous seeds as well as aqueous leaves.

\section{Determination of "Bioactive Extracts"}

The determination of the chemical composition of the aqueous extracts was carried out thanks to the gas chromatography phase (GCP) coupled with a mass spectrophotometer. GCP analysis of constituents of seeds revealed 43 peaks corresponding to 43 different components by their concentrations. The main compounds obtained are erroneously linear alkanes of $\mathrm{C}_{\mathrm{N}} \mathrm{H}_{\mathrm{N}}$ crude formula. These components are not normally of interest for the present work because the secondary metabolisms of $P$. harmala seeds are mainly alkaloids. This may be due to possible contamination during fitting.

In addition, the GCP has detected for the leaves, 10 components. The 1, 2-benzenedicarboxylic acid, diisooctyl ester file type is the most frequently found with a rate of $96.8 \%$ compared to the other 9 components.

\section{Biological Tests}

Effect by contact of the aqueous extracts of seeds: Figure 2 shows that the population treated with the AqE recorded progressive mortality according to dose and duration of treatment. The highest mortality rate $(90 \%)$ was recorded on the 3rd day, with the highest dose $(2.4 \mathrm{~g}$ / l). This is the same result obtained with the positive control (Aceplan). On the other hand, the lowest dose $(0.3$ $\mathrm{g} / \mathrm{l}$ ) had no effect on the larvae during the first day and 
caused only $30 \%$ mortality on the 3rd day of treatment. The other doses ( 0.6 and $1.2 \mathrm{~g} / \mathrm{l}$ ) had an average effect on the larvae of $C$. barbarus (between $40 \%$ and $60 \%$ ). It should be noted that all these results are compared with the negative control (distilled water). The following regression equation can be obtained by adjusting the cumulative mortality percentages (mortality after three days of treatment) as a function of the doses: $y=28.406 x$ +23.043 (Figure 3). The correlation coefficient (r) is equal to 0.9942 (very strong correlation between dose and mortality). Thus, $99.42 \%$ of the mortality variation in the $C$. barbarus population is due to the AqE treatment effect of $P$. harmala seeds by contact. Similarly, analysis of variance (ANOVA) (Table 1) revealed a significant difference between doses and mortality rate $(\mathrm{P}$ equal to 0.024, therefore less than 0.05).In consequence, the higher the dose and the higher the mortality. To calculate LD 50 (lethal dose to kill $50 \%$ of the population), doses are converted to log doses and cumulative mortality in Probit. The result is recorded in Table 2. The linear regression line of cumulative mortality probabilities as a function of the logarithm of the doses against the larvae is shown in Figure 4. The calculation of the LD50 from the equation of the regression line $y=1.97 x+5.33$ shows that the dose of $0.67 \mathrm{~g} / \mathrm{l}$ caused a mortality of $50 \%$ (Table 3).

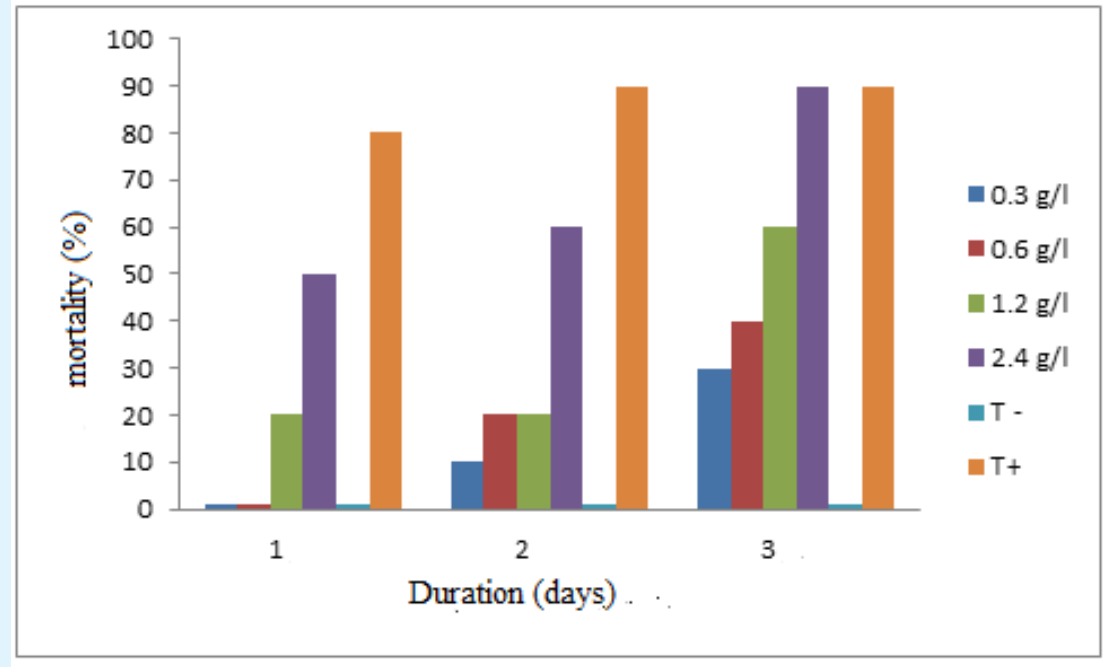

(T: negative control, $\mathrm{T}+$ : positive control)

Figure 2: Effect by contact of AqE of seeds.

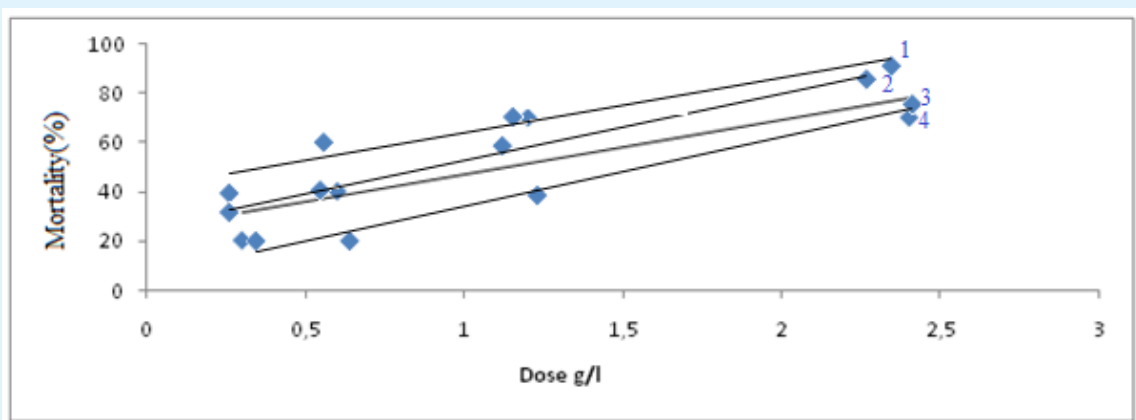

Aprivations: $(1) \mathrm{y}=21.449 \mathrm{x}+40.87(\mathrm{r}=0.9157) ;(2) \mathrm{y}=28.406 \mathrm{x}+23.043(\mathrm{r}=0.9942)$;

(3) $y=22.029 x+25.217(r=0.6976) ;(4) y=15.072 x+13.043(r=0.9797)$.

Figure 3: Linear regression line of dose- mortality by contact of AqE' seeds (2), of AqE' leaves (4) and by ingestion of AqE' seeds (1), of AqE' leaves (3) on C. barbarus larvae. 


\section{International Journal of Zoology and Animal Biology}

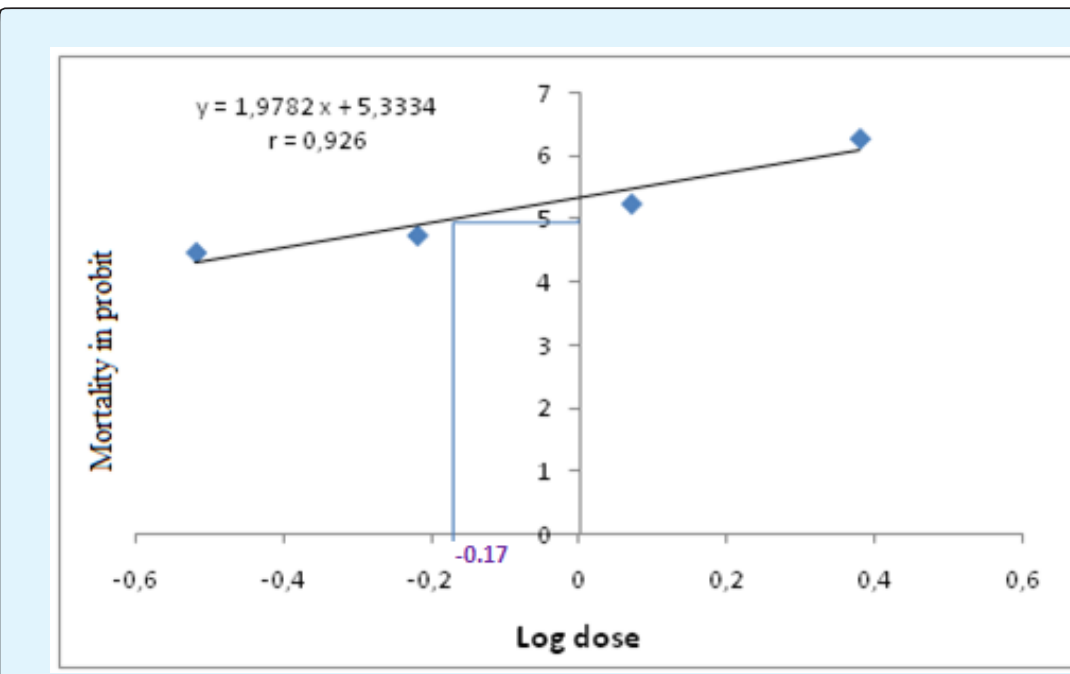

Figure 4: determination of the LD50 for the test of seeds.

\begin{tabular}{|c|c|c|}
\hline Mode of action & AqE' seeds & AqE' leaves \\
\hline contact & $0,02432001<0.05 \mathrm{~S} \mathrm{D}$ & $0,02220283<0.05 \mathrm{~S} \mathrm{D}$ \\
\hline ingestion & $0,00769298<0.01 \mathrm{~V} \mathrm{~S} \mathrm{D}$ & $0,02591312<0.05 \mathrm{~S} \mathrm{D}$ \\
\hline
\end{tabular}

Aprivations: S D: Significant Difference V S D: Very Significant Difference.

Table 1: Probability obtained by analysis of the variance (ANOVA) for different extracts.

\begin{tabular}{|c|c|c|c|c|c|c|}
\hline \multirow{2}{*}{ Dose (g/l) } & \multirow{2}{*}{ Log dose } & mode of action & Cumulative mortality (\%) & \multicolumn{2}{|c|}{ Probit } \\
\cline { 3 - 7 } & & & S & L & S & L \\
\hline \multirow{2}{*}{0.3} & \multirow{2}{*}{0.522} & C & 30 & 20 & 4.48 & 4.16 \\
\cline { 3 - 7 } & \multirow{2}{*}{0.221} & I & 40 & 20 & 4.75 & 4.16 \\
\cline { 3 - 7 } & \multirow{2}{*}{0.6} & C & 40 & 20 & 4.75 & 4.16 \\
\hline \multirow{2}{*}{1.2} & \multirow{2}{*}{0.38} & I & 60 & 40 & 5.25 & 4.75 \\
\cline { 3 - 7 } & & I & 70 & 70 & 5.52 & 5.48 \\
\hline \multirow{2}{*}{2.4} & C & 90 & 50 & 6.28 & 5 \\
\hline
\end{tabular}

Aprivations: C: Action by contact, I: Action by ingestion, S: seeds, L: leaves.

Table 2: Logarithms of doses and Probit of cumulative mortality according to the test of AqE of seeds and leaves by contact and by ingestion.

\begin{tabular}{|c|c|}
\hline Log dose & Dose \\
\hline-0.17 & $0.67 \mathrm{~g} / \mathrm{l}$ \\
\hline 0.48 & $3.01 \mathrm{~g} / \mathrm{l}$ \\
\hline-0.34 & $0.45 \mathrm{~g} / \mathrm{l}$ \\
\hline-0.07 & $0.85 \mathrm{~g} / \mathrm{l}$ \\
\hline
\end{tabular}

Table 3: $\log$ dose and dose of $\mathrm{LD}_{50}$.

Effect by contact of the aqueous extracts of leaves: Regarding the leaves, it should be noted that the results obtained are less important. They vary between $10 \%$ recorded with the dose $1.2 \mathrm{~g} / \mathrm{l}$ at the first day up to $50 \%$ obtained with the dose $2.4 \mathrm{~g} / \mathrm{l}$, the third day of treatment (Figure 5). The linear regression equation obtained is: $\mathrm{y}=$ $15.072 \mathrm{x}+13.043$, (Figure 3), with a correlation coefficient of $97.97 \%(r=0.9797)$. Variation in mortality rates is due at different doses used. Concerning the ANOVA test (Table 1 ), the probability (P) is equal to 0.022 , that is to say less than 0.05 . There is a significant difference between the effects of different doses on insect 
mortality. The regression of cumulative mortality probabilities as a function of the logarithm of the test doses for the AqE of leaves is given in Table 2 and Figure
6. These last show a log dose of 0.48 corresponding to a LD50 of $3.01 \mathrm{~g} / \mathrm{l}$ (Table 3).
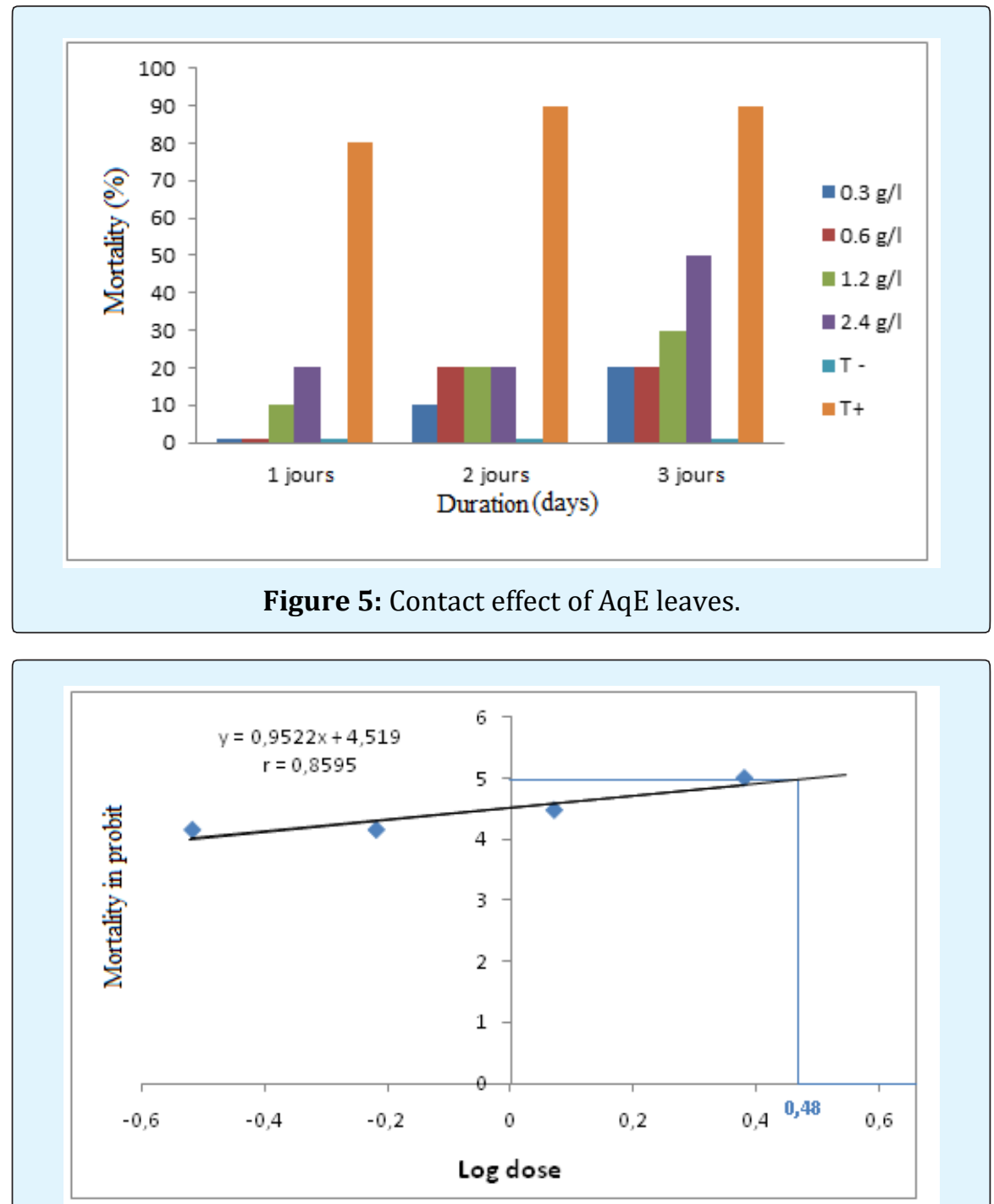

Figure 6: Determination of the LD 50 for the AqE test of leaves.

\section{Comparative Effect of Contact Tests}

The comparative efficacy of the two contact "bioactive extracts" against C. barbarus juveniles is discussed in Figure 7. It should be noted that seeds AqE are more effective than those of leaves. It should be noted that this difference was confirmed by comparing the respective LD
$50 \mathrm{~s}$ for the two bioactive substances. In fact, to kill $50 \%$ of the population of $C$. barbarus, a single dose of $0.67 / 1$ was required for the AqE of seeds. While to obtain this same rate, the AqE of the leaves required a much higher dose $(3.01 \mathrm{~g} / \mathrm{l})$. 


\section{International Journal of Zoology and Animal Biology}

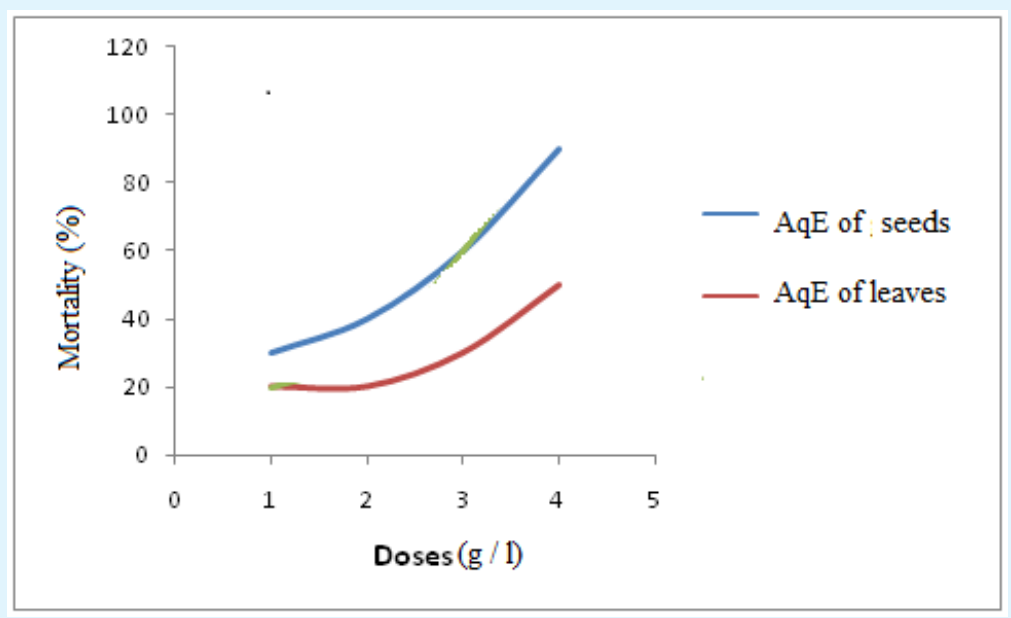

Figure 7: Comparison between the insecticidal effects by contact of the 2 "bioactive extract".

\section{Effect by Ingestion of the AqE of Seeds}

The results obtained for the ingestion efficacy tests are summarized in Figure 8. The AqE of seeds did not start to act until the 4th day. The mortality rate then evolved according to the concentration gradient (from the lowest to the highest). On day 6 , the mortality rate reached the peak of $90 \%$ obtained with the dose of $2.4 \mathrm{~g} / \mathrm{l}$, as the positive control (Figure 8). For statistical analyzes, the correlation coefficient is calculated from the linear regression line of mortality rates as a function of doses: $y$ $=21.449 x+40.87$ (Figure 3 ) with a correlation coefficient $r$ of 0.9157 . The latter shows that $91.57 \%$ of the variation in the effect of the extracts of seeds is due to the variation of the doses.

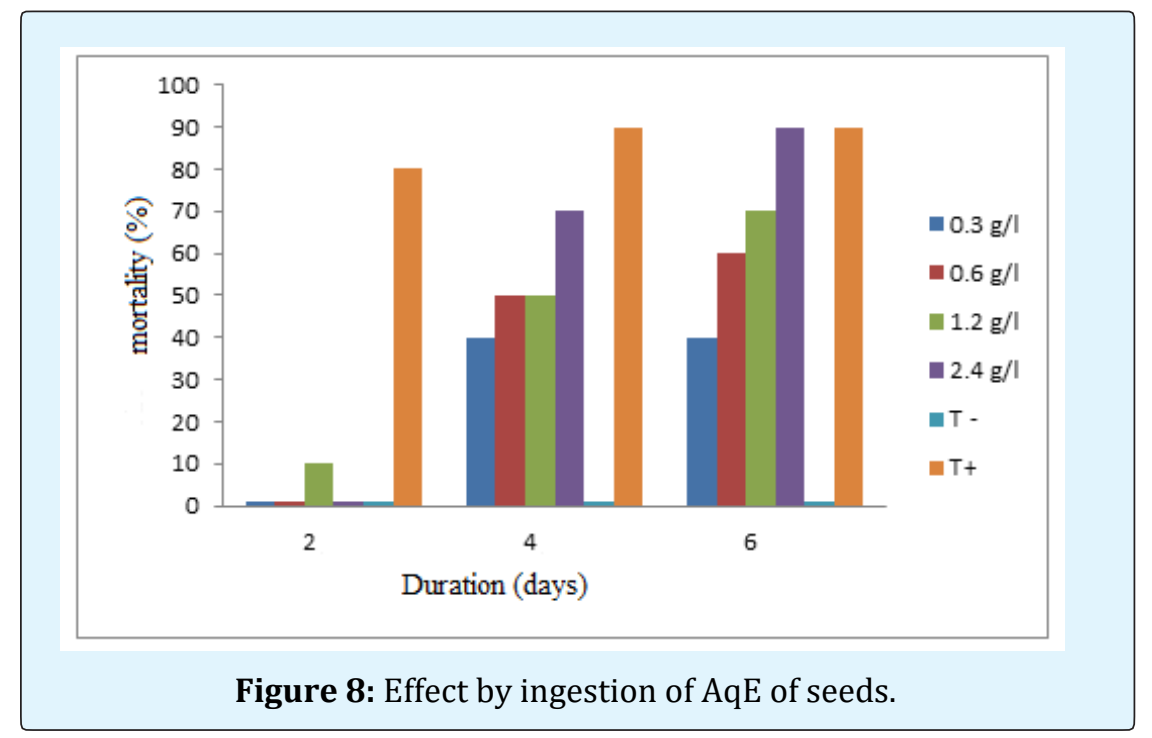

In addition, the ANOVA test (Table 1) indicated that there is a very significant difference between doses and mortality rates $(P=0.007$, therefore less than 0.01).Thus, the higher the dose, the greater the mortality. The linear regression line is calculated from Table 2 and Figure 9: y $=1.6169 \mathrm{x}+5.5648$. This yielded a LD 50 of $0.45 \mathrm{~g} / \mathrm{l}$ (Table 3). 


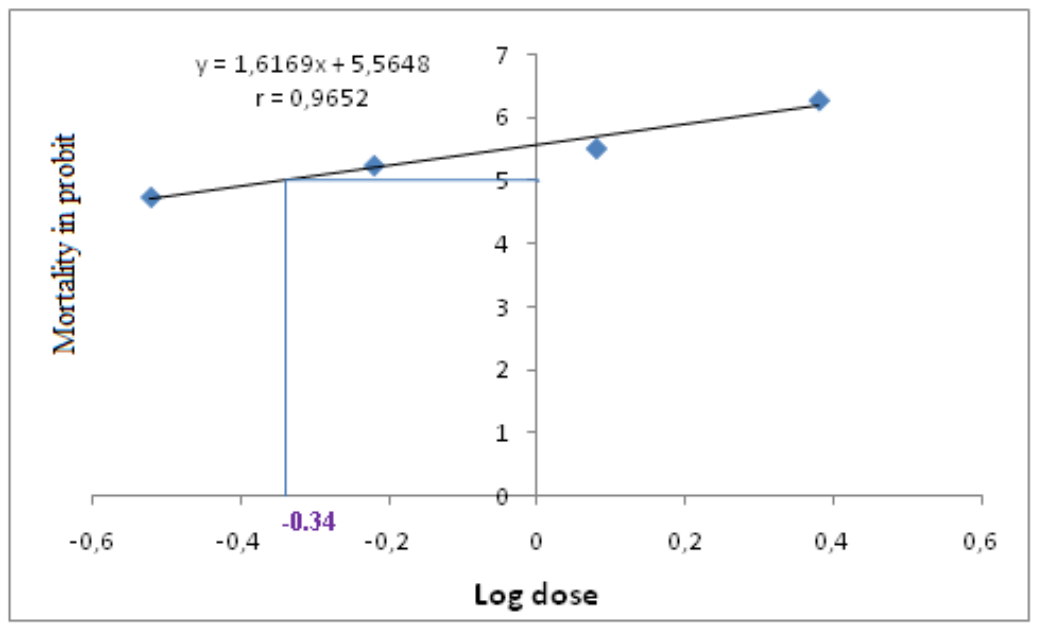

Figure 9: Determination of the LD 50 for the ingestion test of AqE of seeds.

\section{Effect by Ingestion of the AqE of Leaves}

With regard to leaves AqE (Figure 10), almost the same is true of the fact that mortality among the population of $C$. barbarus also decreased especially for low doses $(0.3$ and $0.6 \mathrm{~g} / \mathrm{l})$. It should be noted that at the 6th day, the same mortality rate $(70 \%)$ is mentioned respectively for the doses 1.2 and $2.4 \mathrm{~g} / \mathrm{l}$. The equation of the linear regression line for this test is: $\mathrm{y}=22.029 \mathrm{x}+$ 25.217 with a correlation coefficient $r=0.6976$ (Figure 3 ). Compared with other tests, this coefficient showed a low correlation between the mortality rate and the doses. For the ANOVA test (Table1), a probability of $0.025(\mathrm{P}=0.025$ $<0.05$ ) is obtained. There is therefore a significant difference between mortality rates and doses. The use of the data (Probit of Mortality and Log Doses) recorded in Table 2 has made it possible to obtain the linear regression line represented in Figure 11. The latter also made it possible to obtain an LD 50 equal to $0.85 \mathrm{~g}$. / l (Table 3).

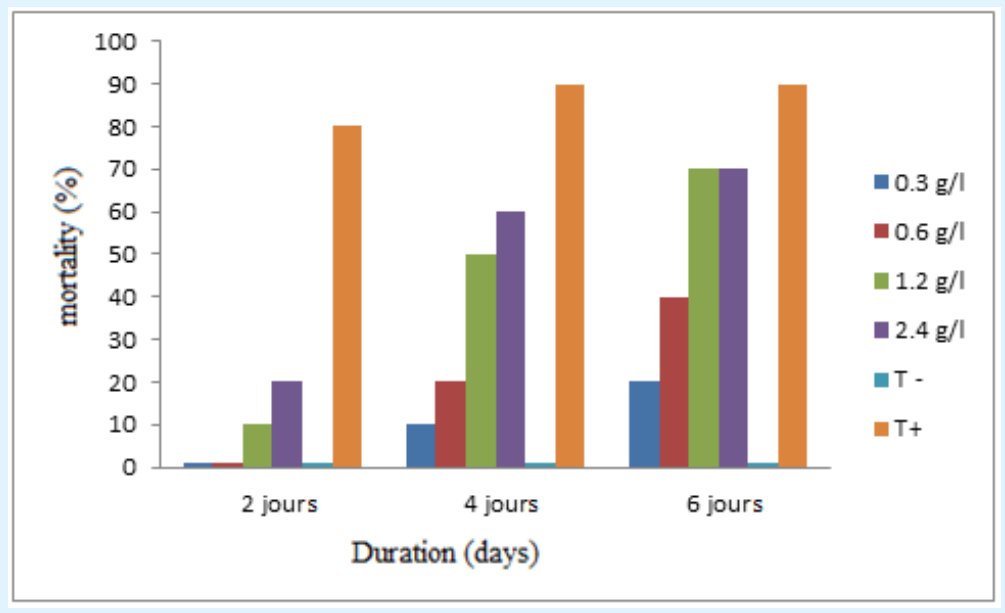

Figure 10: Effect of ingestion of EAq leaves. 


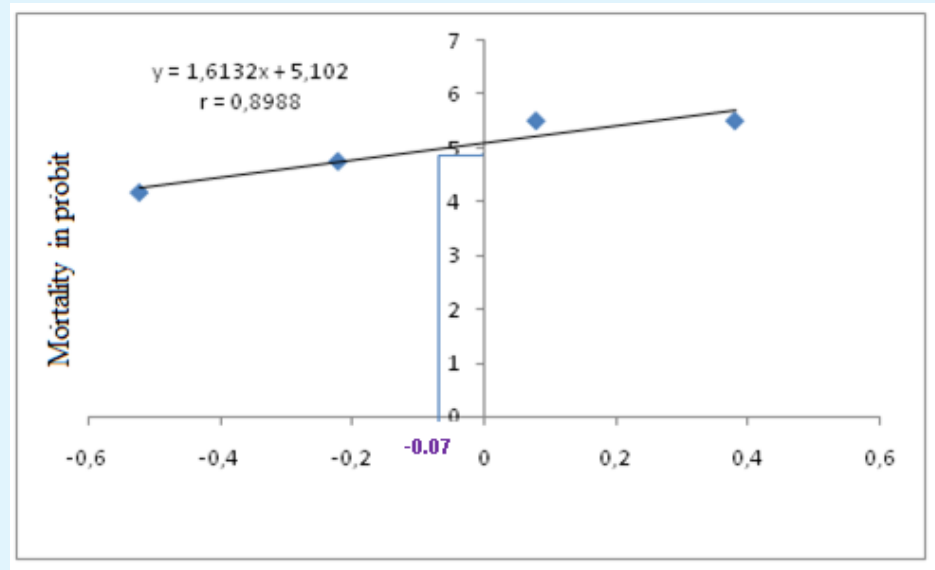

Figure 11: Determination of LD 50 for ingestion test of AqE of leaves.

\section{Comparative Effect of Ingestion Tests}

By comparing the results of the tests of the two "bioactive extracts" by ingestion on the individuals of $C$. barbarus, it is to observe a difference of remarkable mortality between the two. This difference is shown in Figure 12 which allowed knowing the comparative effect of different bioactive substances. In this respect, it should be noted that there is on one side an effect of the AqE of seeds more important than that of leaves. This difference in mortality rate is, as for the contact treatment, due mainly to the variation in the chemical composition of the various constituents and their contents in the various organs of the plant ingested.

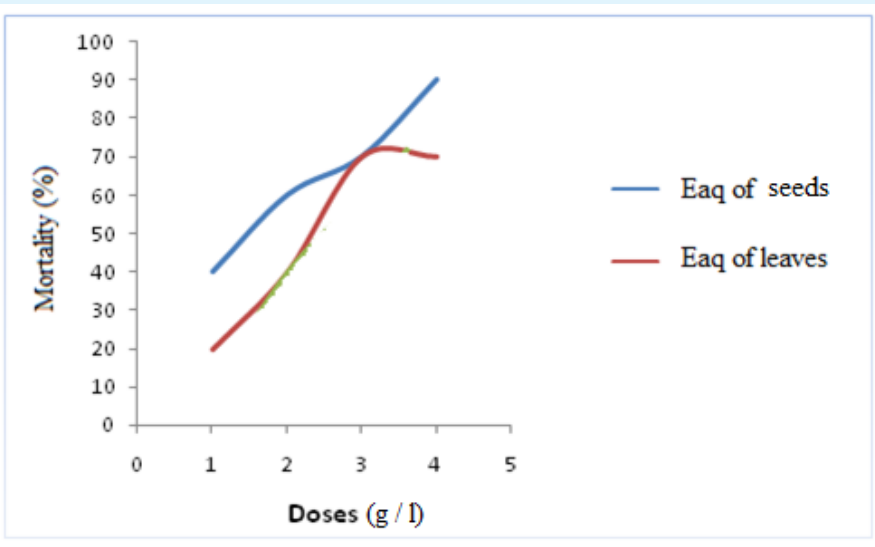

Figure 12: Comparison between the insecticidal effect by ingestion of the two "bioactive extract".

\section{Comparison between the Two Modes of Action (by Contact and by Ingestion)}

The results compared in pairs are shown in Figures 13,14 . After 3 days of contact treatment, a result $(90 \%)$ similar to that recorded 6 days after ingestion treatment is obtained for the seeds (Figure 13). This difference in mortality time is interpreted by the difference between the faster mode of penetration by contact than by ingestion. Concerning the AqE of leaves, the situation is a 
little different since their effect by ingestion is more important than that by contact (Figure 14).

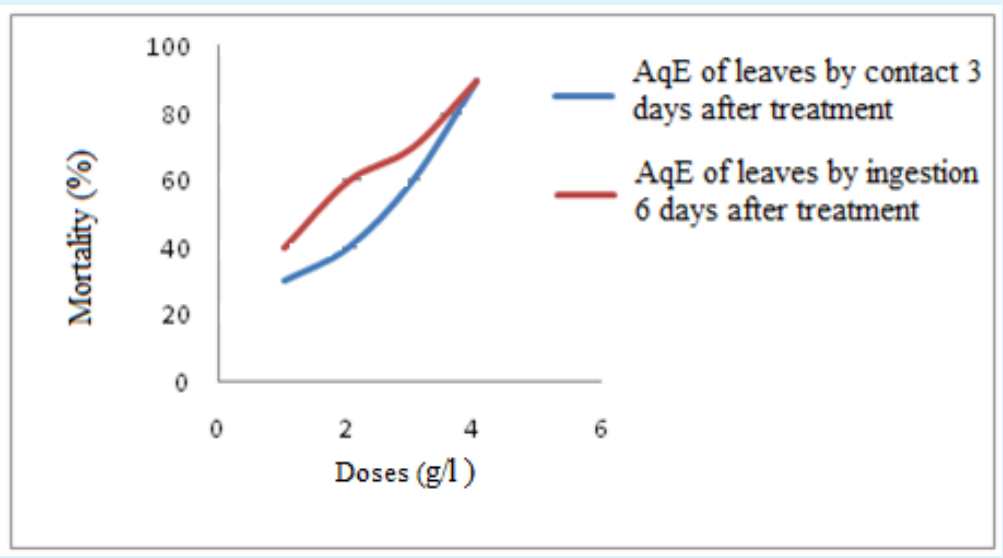

Figure 13: Comparison between the insecticidal effect by ingestion and contact of $t$ seeds.

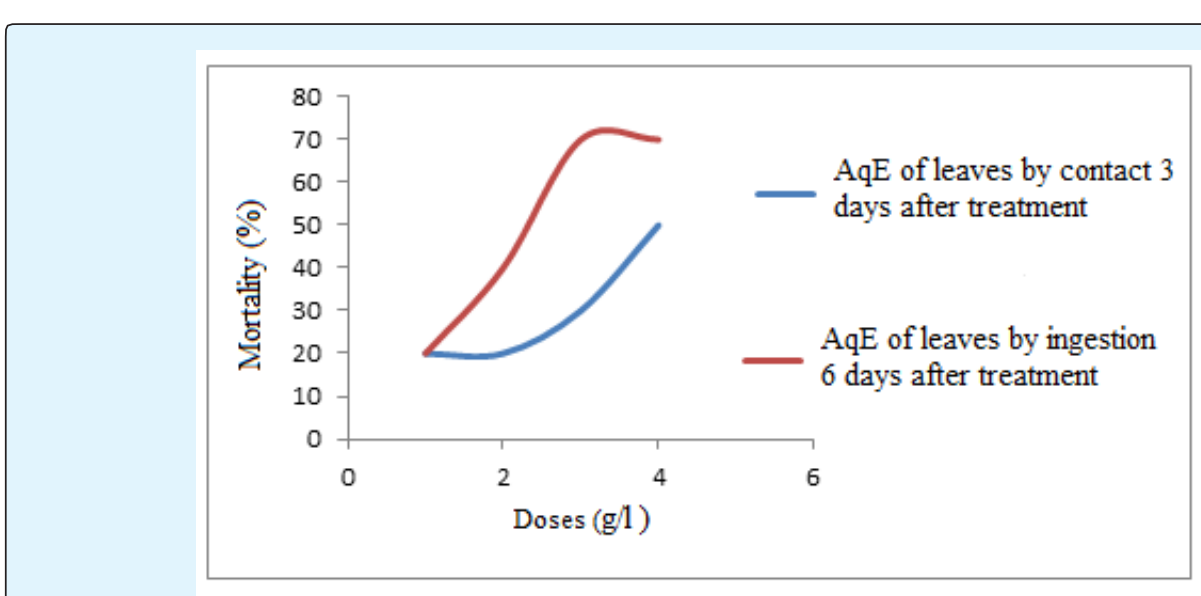

Figure 14: Comparison between insecticidal effect by ingestion and contact of AqE of leaves.

\section{Discussion}

Comparing the yield of aqueous extracts of P. harmala seeds with that obtained by Farouk, et al. [16], namely $6.1 \%$, it should be noted that the result of this work is higher (8\%). For the raw extract, the yield obtained in this study $(11 \%)$ is better than that reported by Singh, et al. [17], equal to $5.1 \%$. But this yield is lower than that obtained by Baghiani, et al. [18], 18.6\%, having used other extraction methods. It should be noted that in P. harmala, the optimal exploitation of these natural products is possible if the harvesting of the plant material occurs during the phase vegetative growth [19].
According to Maruthu-Pandian, et al. [20] the 1,2benzenedicarboxylic acid, diisooctyl file type ester identified among leaf extracts of $P$. harmala is considered an antimicrobial and an antifouling. In addition, among these constituents, oleic acid and linoleic acid (unsaturated fatty acids) predominate. On the other hand, small amounts of palmitic acid and stearic acid (saturated fatty acids) are present [21].

By studying the toxic effect of AqE of $P$. harmala seeds by contact on larvae of 5 th stage (L5) of the locust: Schistocerca gregaria, Benzara, et al. [7] first obtained a low mortality rate of not more than $26 \%$ with doses of 0.3 and $0.6 \mathrm{~g} / \mathrm{l}$. Then this rate increased to $50 \%$ with doses 


\section{International Journal of Zoology and Animal Biology}

1,2 and 2,4 g / l. These extracts are therefore more effective on the L2 and L3 of C. barbarus than on the L5 of $S$. gregaria. This may be due to the difference in developmental stages, with L2 and L3 showing greater sensitivity than L5 of $S$. gregaria, which are more resistant.

With regard to the aqueous extracts of leaves, Idrissi Hassani, et al. [12] reported a 55\% mortality rate for Desert Locust L4 at a dose of $3 \mathrm{ml} / \mathrm{l}$. It should be noted, therefore, that with a mortality approaching $50 \%$ for the present work, the contact effect of the AqE leaves of the Harmal on the two species of locusts, C. barbarus and $S$. gregaria, is almost the same. The last locust species, the action of these same extracts led to a decrease in food intake, a reduction in motility and disruption of reproductive function [11]. This action also caused a blockage of ovarian development in females [6].

In addition, Benzara, et al. [14] by contact testing the effect of " Harmal " seeds on Locusta migratoria L5, obtained a low mortality rate estimated at $30 \%$ for the 0.3 and $0.6 \mathrm{~g} / \mathrm{l}$ doses. On the other hand, this mortality increased significantly with doses of 0.12 and $0.24 \mathrm{~g} / \mathrm{l}$, for which this rate reached respectively $60 \%$ and $80 \%$. These results are fairly close to $10 \%$.

For the treatment of P. harmala by ingestion, Benzara, et al. [14] recorded 30 and $40 \%$ mortality rates. These are obtained with doses of 0.03 and $0.06 \mathrm{mg} / \mathrm{ml}$. By increasing these concentrations to 0.12 and $0.24 \mathrm{mg} / \mathrm{ml}$, the mortalities reach respectively 70 and $90 \%$. For the current work, similar results are obtained, but with doses 10 times higher, ie 1.2 and $2.4 \mathrm{~g} / \mathrm{l}$.

By testing the ingestion activity of AqE of $P$. harmala during the flowering period on the L4 of the Desert Locust (S. gregaria), Abbassi, et al. [11] recorded a mortality rate of $75 \%$. It should be noted from this information that the $\mathrm{AqE}$ of Harmal have proved, to varying proportions, their effectiveness against locusts. This efficacy is justified by a histological study in the middle intestine of $S$. gregaria [13]. In this study, it is shown that the Desert Locust has a reduction in external circular musculature. The latter led to a relaxation of the intestine and atrophy of the intestinal mucosa with reduced striated epithelium. The mesenteric epithelium in turn exhibits a granular appearance, an altered brush border, and typical signs of cellular necrosis [21]. These results may be explained in the work on extracts of $P$. harmala, which showed that alkaloids (alkane for the present case) are responsible for toxicity in insects. These alkaloids act through harmalol and harmol [21]. But, they act mostly through harmine and harmaline. These are two substances present at all the phenological stages of the plant and more particularly at the maturation stage of the seeds and roots. During this last stage, the rate varies from 2 to $7 \%$ compared to the foliage where only $0.5 \%$ is recorded comparing the two modes of action with each other Idrissi Hassani, et al. believe that in S. gregaria individuals, fed by ingestion through $P$. harmala leaves, there was a direct effect on epithelial cells and thus an inhibition of absorption and assimilation. In addition, there was an indirect effect with absorption of metabolites but without assimilation $[7,13,22]$. On the other hand for Benzara, et al. [14] the bio-pesticidal effect by seeds induced contact of $P$. harmala is less compared to ingestion treatment, despite the fragility of the larval cuticle.

\section{Conclusion}

In order to combat C. barbarus a potential pest of crops, "bioactive extracts" have been extracted from seeds and leaves of $P$. harmala an important medicinal plant. These substances have been applied as bio insecticidal by contact and by ingestion against juveniles of barbarian locust (L2 and L3). The results recorded after the biological tests were very satisfactory. After treatment of the larvae, the best efficacy was obtained using aqueous extract of $P$. harmala seeds used by contact at the dose of $2.4 \mathrm{~g} / \mathrm{l}$ (total mortality after 3 days of treatment). It is the same result obtained with the positive control (Aceplan) with which the mortality rate is $90 \%$.

It should be noted that for all "bioactive extracts", the lowest mortality rates are recorded with the lowest doses either by ingestion ( 6 days) or by contact ( 3 days). For example, the seeds aqueous extracts caused only 30 to $40 \%$ with the dose of $0.3 \mathrm{~g} / \mathrm{l}$.

The insecticidal effect by contact of AqE' seeds are evaluated by a LD50 of $0.67 \mathrm{~g} / \mathrm{l}$. regarding the effect by ingestion for the same "bioactive extract", the LD50 recorded is 0.45 . Whereas for the AqE of leaves, it is to register a LD50 of $3.01 \mathrm{~g} / \mathrm{l}$ by contact and $0.85 \mathrm{~g}$. / $/ \mathrm{l}$ by ingestion.

It should also be noted that these results are obtained with only the active ingredients without any adjuvant. It will be interesting to know what their effect will be by adding substances such as stabilizers, surfactants or other antioxidants and synergists. 


\section{International Journal of Zoology and Animal Biology}

\section{References}

1. Clemente ME, Garcia MD, Presa JJ (1987) Morphometric and pigmentary variation in Calliptamus barbarus (Costa, 1836) in relationship with environment, and its taxonomic value, in Evolutionary Biology of Orthopteriod insects. In: Boccetti, et al. (Eds.), Ellis Homood Ltd, Chichester pp: 184-189.

2. Benzara A (2004) Geographical polymorphism of the species Calliptamus barbarus (Costa, 1836) (Orthoptera: Acrididae) in Algeria. Doctoral thesis. In: s Nat. Agro., El Harrach, Algiers pp: 154.

3. Larrosa E, Ggarcia MD, Clemente ME, Presa JJ (2004) El behavioramiento encautividad de Calliptamus barbarus (Orthoptera: Acrididae). Memoirs of the Italian Entomological Society 82(2): 615-630.

4. Rouibah M, Lopez LA, Presa J, Doumandji S (2016) A molecular phylogenetic and phylogeographic study of two forms of Calliptamus barbarus. (Costa 1836) (Orthoptera: Acrididae, Calliptaminae) from two regions of Algeria. Annales de la Société entomologique de France 52(2): 77-87.

5. Regnault Roger C, Vincent C, Philogene BJR (2002) Phytosanitary products, insecticides of plant origin: promises of yesterday and today. In: Plant-based bio pesticides. Lavoisier, et al. (Eds.), TEC and DOC, Paris pp: 1013.

6. Idrissi Hassani LM, Ould Ahmedou MA, Chihrane J, Bouaichi A (1998) Effects of a diet of Peganum harmala (Zygophyllaceae) on the survival and ovarian development of the desert locust Schistocerca gregaria Forskal (Orthoptera, Acrididae), Ethnopharmacologia 23: 26-41.

7. Benzara A, Khalfi Habes O, Lazib Z (2010) Effectiveness of aqueous extracts of Peganum harmala (Zygophylaceae) on the L5 larvae of the Desert Locust, Schistocerca gregaria (Forsskâl, 1775) (Orthoptera, Acrididae). Procedures of the $7^{\text {th }}$ Congress of the Moroccan Plant Protection Association, Rabat pp: 469-474.

8. Kemassi A, Hellali N , Boual Z , Bouziane N, Ould El Hadj-Khelil A, et al. (2013) Compared toxicity of raw leaf essential oils of three spontaneous plants collected in the algerian sahara on larvae and adults of schistocerca gregaria (forskål, 1775) (Orthoptera:Cyrtacanthacridinae). Algerian journal of arid environment 3(2): 34-42.

9. Kemassi A, Bouziane N, Boual Z, Ould El Hadj MD (2014) Biological activity of the essential oils of Peganum harmala L. (Zygophyllaceae ) and Cleome arabica L. ( Capparidaceae ) on Schistocerca gregaria (Forskål, 1775). Phytothérapie 12: 348-353.

10. Abbassi K, Mergaoui L, Atay Kadiri Z, Stambouli A, Ghaout S (2003) Biological activity of Peganum harmala seed extract on the Desert Locust (Schistocerca gregaria Forskål 1775). Journal of Orthoptera Research 12(1): 71-78.

11. Abbassi K, Mergaoui L, Atay Kadiri Z, Gaout S, Stambouli A ( 2005) Activités biologiques des feuilles de Peganum harmala (Zygophyllacea) en floraison sur la mortalité et l'activité génésique chez le Criquet pèlerin. Faculté des Sciences, Université de Rabat 16: 31-46.

12. Idrissi Hassani LM, Ould Ahmedou ML, Mayad EH, Bouaichi A (2002) Pouvoir insecticide de Peganum harmala sur Schistocerca gregaria: effets de l'huile et des extraits de feuilles. Biologie \& sante 2(2): 122133.

13. Idrissi Hassani L M, Hermas J (2008) Effects of Peganum harmala L. (Zygophyllaceae) feeding on the digestive track of the migratory locust Schistocerca gregaria Forsk. (Orthoptera, Acrididae). Zool baetica 19: 71-84.

14. Benzahra A, Ben Abdelkrim A, Khalfi Habes O (2011) Effect of aqueous extracts of seeds of Peganum harmala L. (zygophyllaceae) on 5th stage larvae Locusta migratoria cinerascens (Fabricius, 1781) (Orthoptera: Oedipodinae). Journal of life science 7(2): 154-163.

15. Mbiantcha M, Kamanyi A, Teponno RB, Tapondjou AL, Watcho P, et al. (2011) Analgesic and AntiInflammatory Properties of Extracts from the Bulbils of Dioscorea bulbifera L. var sativa (Dioscoreaceae) in Mice and Rats. Evidence Based Complementary and Alternative Médicine Article ID 912935, 2011: 9.

16. Farouk L, Laroubi A, Aboufatima R, Benharref A, Chait A (2008) Evaluation of the analgesic effect of alkaloid 
extract of Peganum harmala L.: possible mechanisms involved. J Ethnopharmacol 115: 449-454.

17. Singh BA, Chaturvedi JP, Narender T, Srivastava KA (2008) Preliminary studies on the hypoglycemic effect of Peganum harmala L. Seeds ethanol extract on normal and streptozotocin induced diabetic rats. Indian J Clin Biochem 23(4): 391-393.

18. Baghiani A, Djarmouni M, Boumerfeg S, Trabsa H, Charef N, et al. (2012) Xanthine Oxidase Inhibition and Antioxidant Effects of Peganum harmala Seed Extracts. European Journal of Medicinal Plants 1: 4256.

19. Mayad EH, Idrissi Hassani LM, Ferji Z, Chebli B, El Hadek M ( 2013) Quantitative and Qualitative
Analysis by HPLC of Major Peganum harmala Alkaloids at Different Stages of Development. Journal of Natural Sciences Research 3(11): 104-111.

20. Maruthu Pandian A, Mohan VR (2011) GC-MS Analysis of some bioactive constituents of Pterocarpus marsupium Roxb. International Journal of ChemTech research 35(3): 1652-1657.

21. Idrissi Hassani LM, El Hadek M (1999) Analyse de la composition de l'huile de Peganum harmala L. (Zygophyllacées). Acta botanica Gallica: bulletin de la Société botanique de France 146(4): 353-359.

22. Tahri N, Rhalem N, Soulaymani R (2004) L'intoxication au Harmal, Peganum harmala. Esperance Med 10: 5. 